\title{
Management Tool in the State of Connecticut
}

\section{Introduction:}

3- Department of Environmental Earth Science. Eastern Connecticut State University

In the state of Connecticut public well data repository.

These records span into the 1970s and in their current form they cannot be queried into a database. In addition, these reports are organized by township and the year they were filed which makes it difficult to search for and collect data to study areas of interest.

- For this pilot study the Connecticut Department of Public Health (CT DPH), the University of Connecticut Center for Land Use Education and Research (UConn CLEAR), and the coauthors digitalized 1,700

well completion reports from a Connecticut township into a MS Access database.

Once the records were in the database, certain fields were queried and imported into ArcGIS to create a geodatabase. With the geodatabase we performed a spatial analysis that showed hydrogeological information about the township.

- The results of this study indicate how digitalizing well completion reports are useful for studying bedrock recharge areas, groundwater depth and flow direction, and bedrock aquifer transmissivity. - If a similar project was conducted for the entire state it would be beneficial for managing the water supply and groundwater contamination issues.

\section{Methodology:}

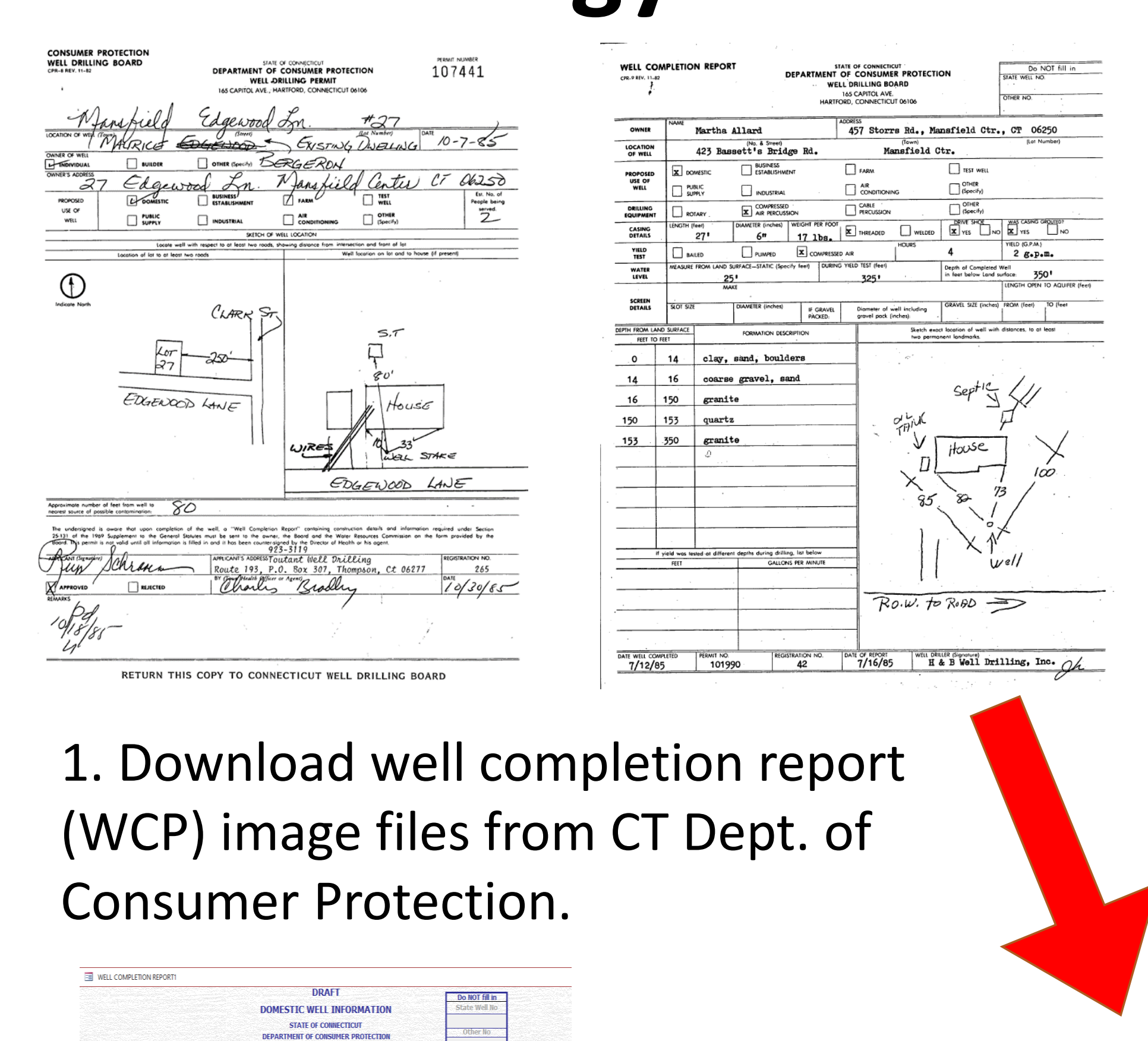

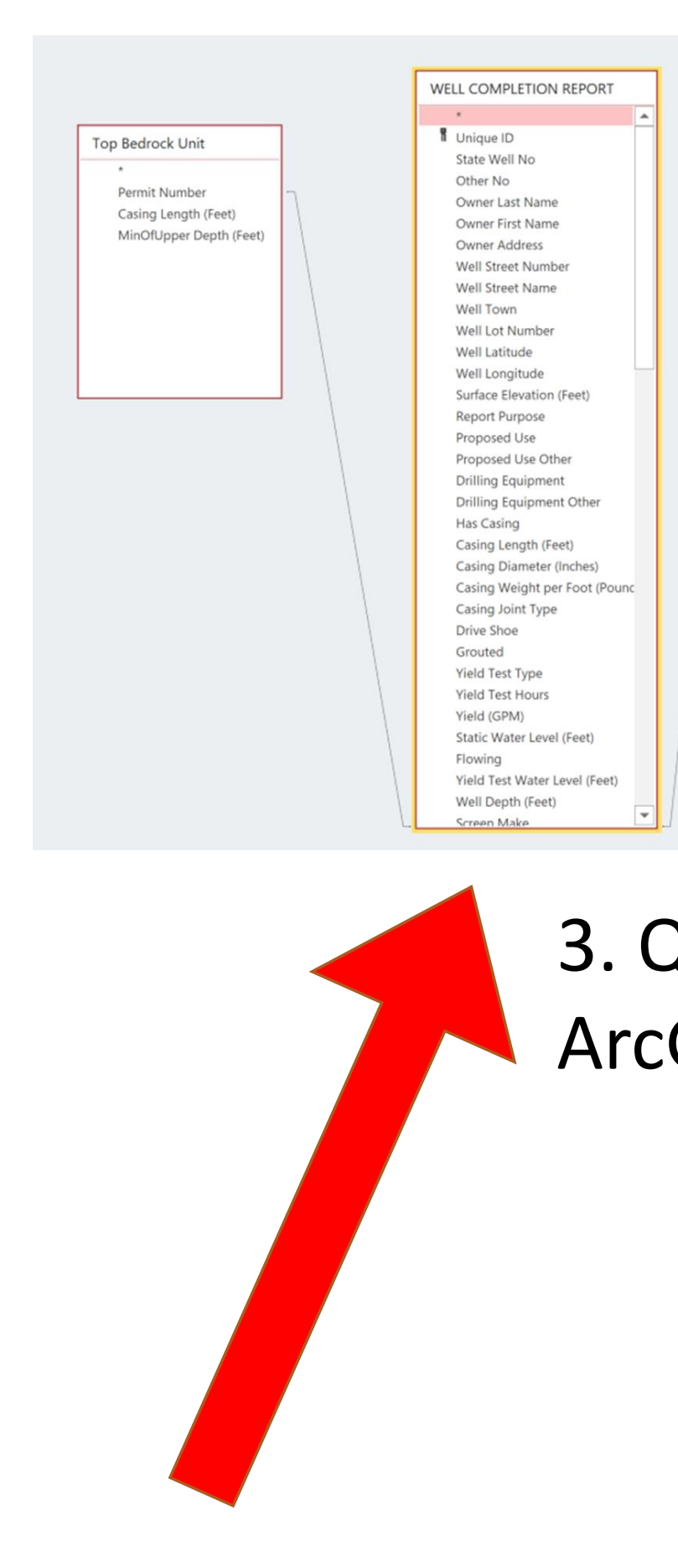

2. Digitalize the WCPs into MS Access database.

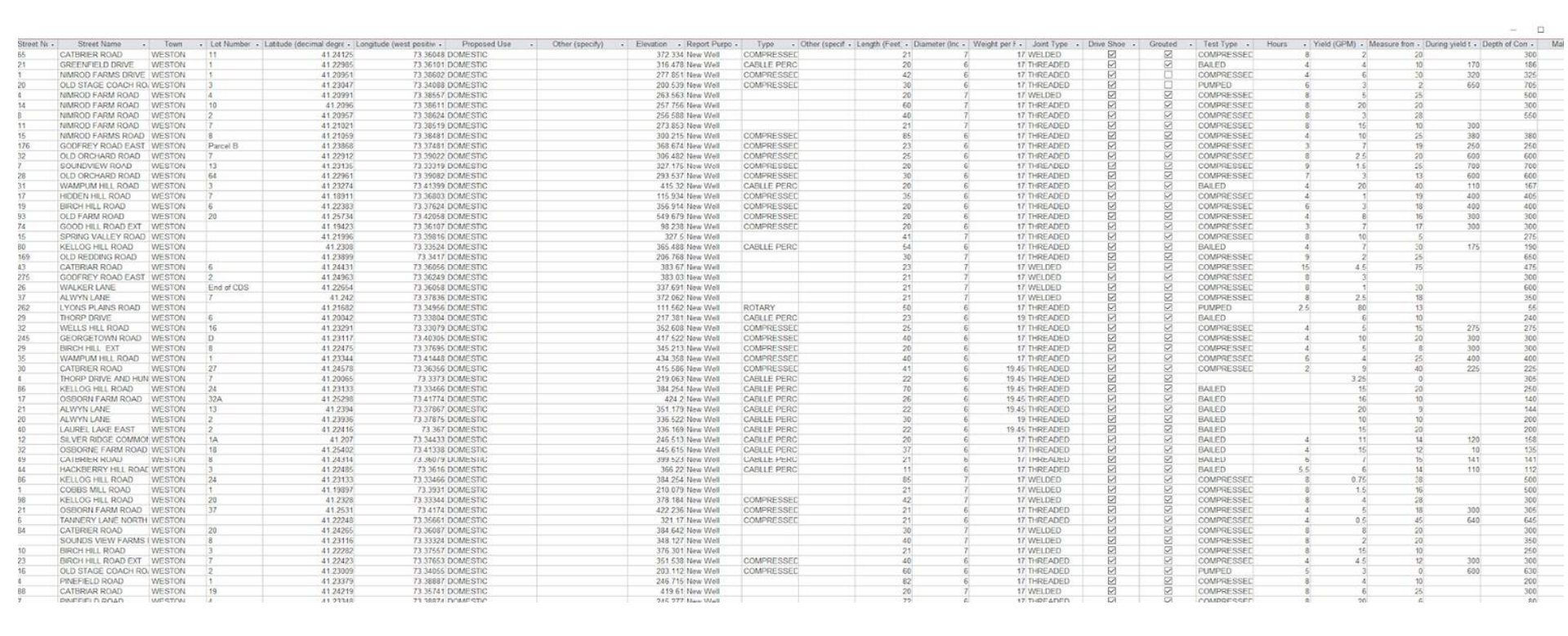

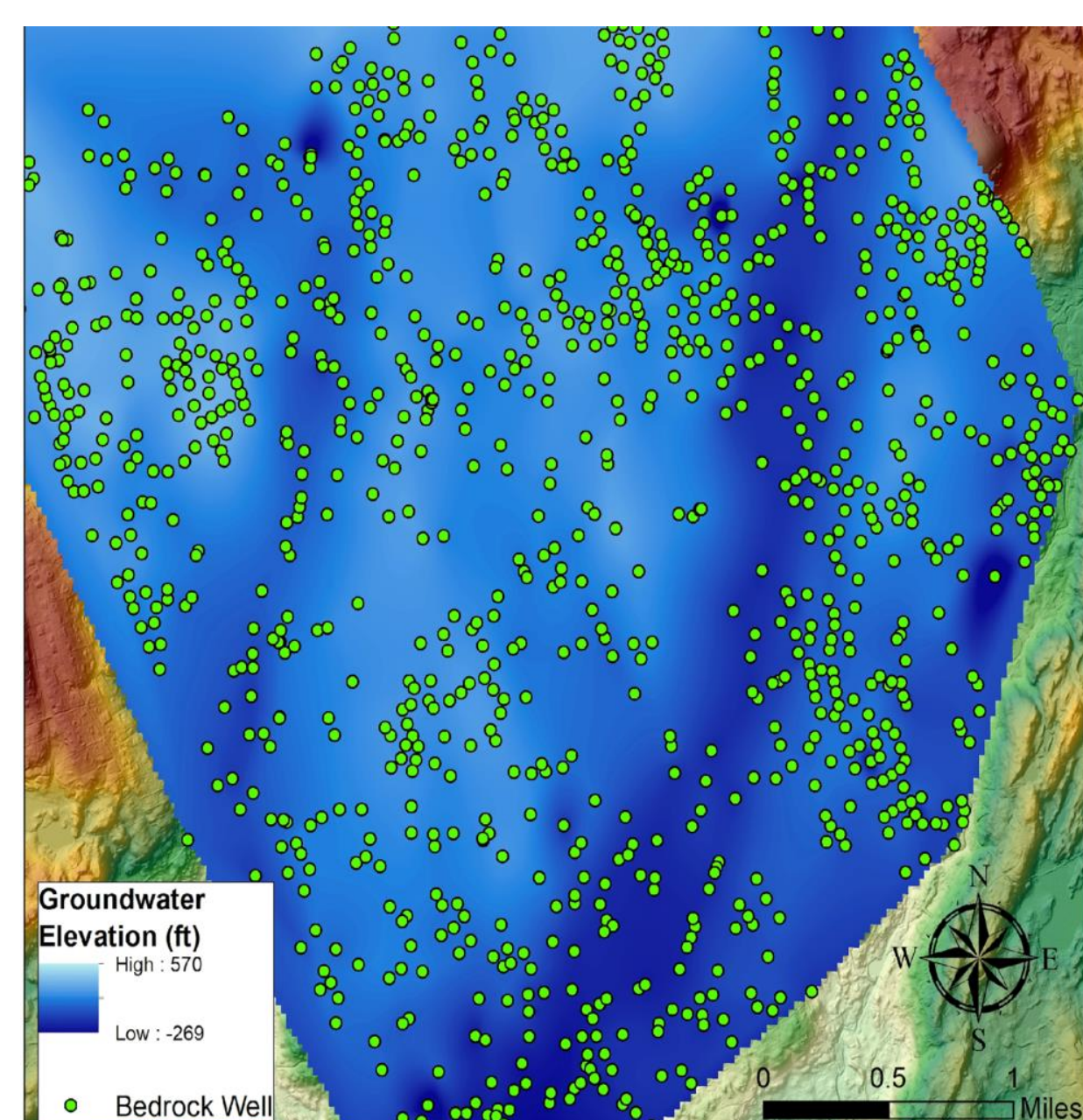
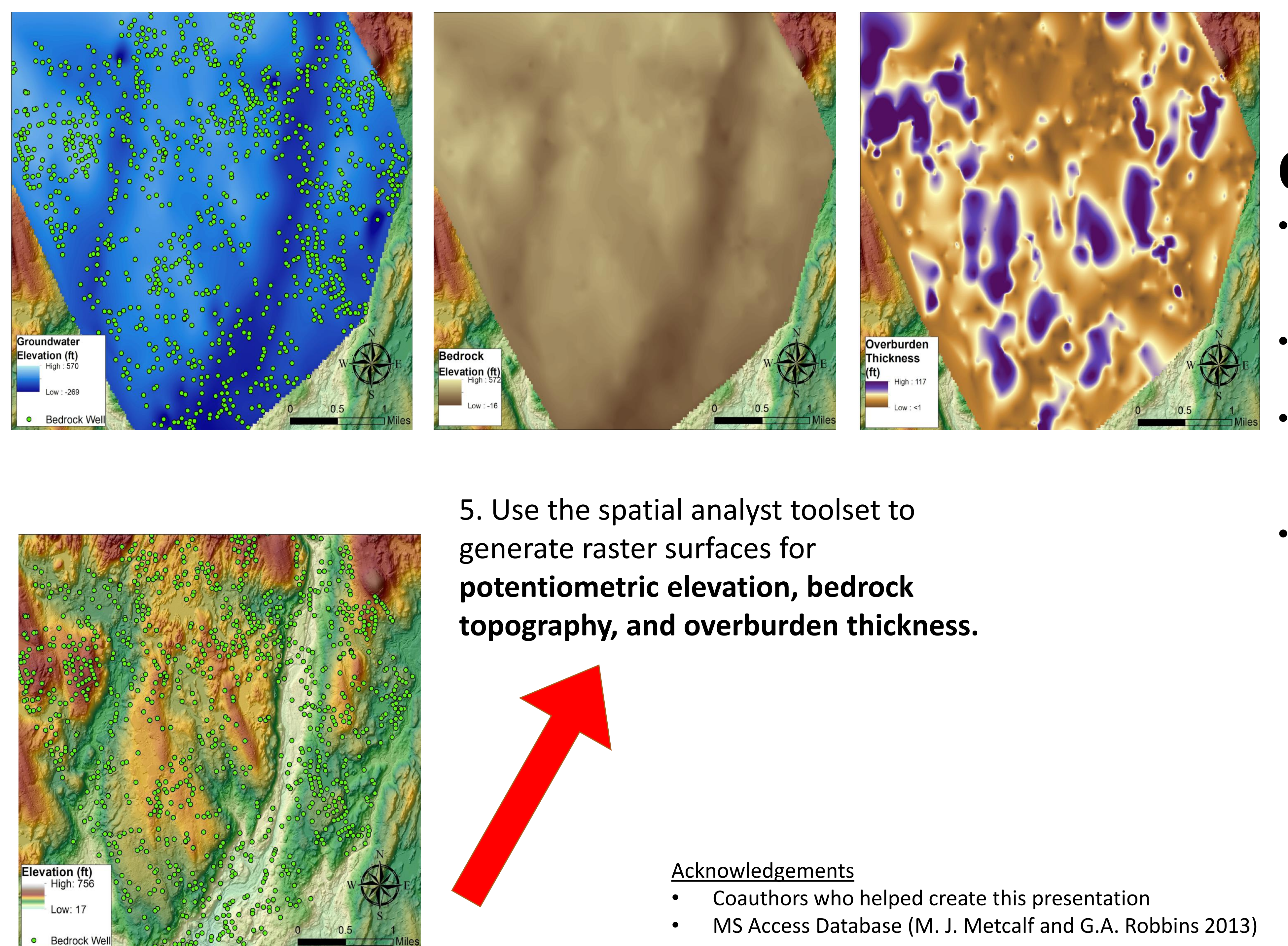

5. Use the spatial analyst toolset to generate raster surfaces for potentiometric elevation, bedrock topography, and overburden thickness.

4. Geocode addresses to approximate the coordinates of each well.

\section{Results:}

The participants were able to digitalize the well completion reports from the early 1970 s to the mid 2010 s.

In addition, this allows natural resource managers and the state township.

Since the pilot study was a success it shows that the process of digitalizing historical well completion reports can be used for other townships.

With that information found the hydrogeologic conditions can be calculated (bedrock depth, bedrock recharge areas, groundwater depth and flow direction, and bedrock aquifer transmissivity).

\section{Conclusions:}

As of February 2021, the CT Department of Consumer Protection under the direction of Jason Cohen has developed a digitized database for data submission and analysis.

The digital database only accounts for records submitted after the creation of this new database.

In order for the older records to be inputted into a database they will need to be digitalized using the process highlighted in this presentation.

- Overall, this pilot study shows how digitalizing historic well records would be useful for assessing hydrological condition and managing water resources in Connecticut. 